\title{
Proteomics method to quantify the percentage of cow, goat, and sheep milks in raw materials for dairy products
}

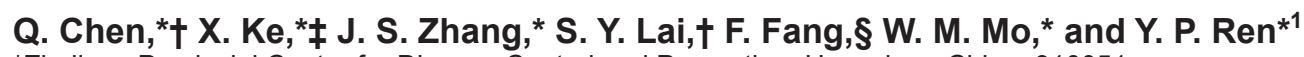 \\ *Zhejiang Provincial Center for Disease Control and Prevention, Hangzhou, China, 310051 \\ †Beingmate Baby and Child Food Co., Ltd., Hangzhou, China, 311106 \\ ¥Zhejiang University of Technology, Hangzhou, China, 310005 \\ §Zhejiang Grain and Oil Product Quality Inspection Center, Hangzhou, China, 310012
}

\begin{abstract}
Fraud in milk and dairy products occurs when cow milk is added to sheep and goat milk for economic reasons. No reliable, selective, and sensitive method exists for quantifying the milk percentage of different species. This work reports the development and validation of a proteomics-based method for the qualitative detection and quantitative determination of cow, sheep, and goat milks in the raw materials used for dairy products. $\beta$-Lactoglobulin was selected as the protein marker because it is a major protein in milk and whey powder. The tryptic peptides LSFNPTQLEEQCHI and LAFNPTQLEGQCHV were used as signature peptides for cow milk and for sheep and goat milks, respectively. The winged peptides LKALPMHIRLSFNPTQL*EEQCHI* and LKALPMHIRLAFNPTQL*EGQCHV* were designed and synthesized as internal standards. Validation of the method showed that it has good sensitivity, specificity, reproducibility, precision, and accuracy. This method is easily applicable in routine laboratory analysis without intensive proteomics background.
\end{abstract}

Key words: cow milk, goat and sheep milk, quantification, signature peptides, $\beta$-lactoglobulin

\section{INTRODUCTION}

The production and consumption of goat and sheep milk (GSM) and their products are increasing (http:// faostat3.fao.org/), in part because of religious concerns, special recipes for local dishes, and the reduction of risk for cow milk (CM) allergy (Park, 1994). Fraud in milk and dairy products has been reported, and it especially takes the form of adding cheaper CM to milk of other species (López-Calleja et al., 2005). To ensure

Received December 10, 2015.

Accepted April 30, 2016.

${ }^{1}$ Corresponding author: renyiping@263.net the reliable quality of final products, it is necessary to develop a highly sensitive, selective, and accurate quantification method for monitoring raw materials in the dairy industry.

Some methods have been developed to evaluate milk authenticity. A DNA-based PCR method is widely used for testing milk authenticity (Abdel-Rahman and Ahmed, 2007; López-Calleja et al., 2007a; Cottenet et al., 2011), but it cannot quantify the percentage of each type of milk because the DNA content in milk is highly variable depending on the health of the cow (RaynalLjutovac et al., 2007). Protein-based ELISA is another widely adopted method (López-Calleja et al., 2007b; Costa et al., 2008; Song et al., 2011), and the ELISA is based on specific antibody-antigen reactions. The antibody recognizes the target protein through a specific epitope, which is also dependent on the 3-dimensional structure of the protein. After thermal denaturation during production, the amount of protein tends to be underestimated.

In recent years, milk authenticity has typically been determined using nonimmunological protein-based methods. Methods based on liquid chromatography, capillary electrophoresis, or mass spectrometry were developed to identify and quantify the percentage of each type of milk in dairy products (Mayer et al., 1997; Cartoni et al., 1999; Ferreira and Caçote, 2003; Czerwenka et al., 2010). However, these methods have not been widely used in routine laboratory analysis because of their limited selectivity and sensitivity in foodstuffs with complicated matrices. The proteomics method as an emerging method with high sensitivity and selectivity has also been applied in the determination of milk adulteration. This method focuses on qualitative (Di Girolamo et al., 2014; Bernardi et al., 2015) or semiquantitative (Camerini et al., 2016) analysis. Milk adulteration driven by economic reasons affects the percentage of milk in dairy products. Based on this concern, an analytical method to quantify exact milk percentages is urgently needed. 
The present study aimed to establish and validate a proteomics-based method for quantifying the percentage of GSM and CM in the major raw material of dairy products, milk powder and whey protein powder. Goat milk is not used to adulterate sheep milk because of their similar economic value and vice versa. From this point of view, one signature peptide (SP) suitable for both goat and sheep milk was selected to reduce the difficulty and cost of analysis. The study introduced a novel internal standard strategy to minimize the matrix effect, which led to more accurate quantification results.

\section{MATERIALS AND METHODS}

\section{Peptide Synthesis}

The isotope-labeled AA Fmoc-Val-OH- ${ }^{13} \mathrm{C}_{5},{ }^{15} \mathrm{~N}$; Fmoc-Ile-OH- $-{ }^{13} \mathrm{C}_{6},{ }^{15} \mathrm{~N}$; and Fmoc-Leu-OH- $-{ }^{13} \mathrm{C}_{6},{ }^{15} \mathrm{~N}$ (98\% isotopic enrichment) were purchased from SigmaAldrich (St. Louis, MO) and used to synthesize the internal standard peptide (IS). Cow milk signature peptide LSFNPTQLEEQCHI, cow milk internal standard LKALPMHIRLSFNPTQL*EEQCHI*, goat and sheep milk signature peptide LAFNPTQLEGQCHV, and goat and sheep milk internal standard LKALPMHIRLAFNPTQL*EGQCHV* were synthesized by ChinaPeptides Co. Ltd. (Shanghai, China). The $\mathrm{L}^{*}, \mathrm{I}^{*}$, and $\mathrm{V}^{*}$ in the peptide sequences indicate Leu-OH- ${ }^{13} \mathrm{C}_{6},{ }^{15} \mathrm{~N}$; Ile-OH- $-{ }^{13} \mathrm{C}_{6},{ }^{15} \mathrm{~N}$; and Val-OH- $-{ }^{13} \mathrm{C}_{5},{ }^{15} \mathrm{~N}$, respectively.

\section{Sample Preparation and Tryptic Digestion}

One gram of sample was placed in a $100-\mathrm{mL}$ volumetric flask, and water was added to $100 \mathrm{~mL}$ to dissolve the sample with shaking. Ten microliters of the sample solution was then mixed with $10 \mu \mathrm{L}$ of IS solution (10 $\mu \mathrm{mol} / \mathrm{L} \mathrm{CM}$ and GSM IS in water), $10 \mu \mathrm{L}$ of dithiothreitol (DTT, $100 \mathrm{mmol} / \mathrm{L}$, Sigma-Aldrich), and 825 $\mu \mathrm{L}$ of water in an Eppendorf tube, and the mixture was incubated in a water bath at $70^{\circ} \mathrm{C}$ for $30 \mathrm{~min}$. After addition of $30 \mu \mathrm{L}$ of indoleacetic acid $(100 \mathrm{mmol} / \mathrm{L}$, Sigma-Aldrich), the mixture was incubated in the dark at room temperature for $30 \mathrm{~min}$. Subsequently, $100 \mu \mathrm{L}$ of ammonium bicarbonate (Sigma-Aldrich) and $10 \mu \mathrm{L}$ of sequence-grade trypsin $(200 \mu \mathrm{g} / \mathrm{mL}$ in $1 \mathrm{mmol} / \mathrm{L}$ $\mathrm{HCl}$ solution, provided by Suxia Li (Fudan University, Shanghai, China) were added into the tube. After incubation for $30 \mathrm{~min}$ in a $37^{\circ} \mathrm{C}$ water bath, the reaction was stopped by adding $5 \mu \mathrm{L}$ of formic acid (Merck, Darmstadt, Germany).

\section{Peptide Identification Using Ultra-Performance Liquid Chromatography Tandem Time-of-Flight Mass Spectrometry}

The tryptic peptides were separated using an Acquity ultra-performance liquid chromatography (UPLC) System equipped with Acquity UPLC binary solvent manager, sample manager, and column manager (Waters, Milford, MA). The column was an Acquity UPLC BEH 300 C18 column (1.7-mm particle size, $2.1 \times 100$ $\mathrm{mm}, 300 \AA$ ) with a guard column of the same material. The temperature of the autosampler and column were kept at 10 and $40^{\circ} \mathrm{C}$, respectively. Mobile phase A was water containing $0.1 \%$ formic acid, and mobile phase $\mathrm{B}$ was acetonitrile (Merck) containing $0.1 \%$ formic acid. The gradient for peptide identification started at $3 \% \mathrm{~B}$ and was linearly raised to $40 \%$ in $20 \mathrm{~min}$. After equilibration at $100 \%$ B for 1 min, the system was conditioned with $3 \%$ B for 3 min before the next injection.

Time-of-flight (ToF) detection was carried out on a Synapt G2 High-Definition MS system equipped with an electrospray ion (ESI) source (Waters). Details of ToF conditions were as follows: mode, ESI+ and $\mathrm{MS}^{\mathrm{E}}$; capillary voltage, $3 \mathrm{kV}$; sampling cone voltage, $25 \mathrm{~V}$; extraction cone voltage, $4 \mathrm{~V}$; source temperature, $100^{\circ} \mathrm{C}$; desolvation temperature, $400^{\circ} \mathrm{C}$; cone gas flow, $30 \mathrm{~L} / \mathrm{h}$; desolvation gas flow, $800 \mathrm{~L} / \mathrm{h}$; ramp trap collision energy, 15 to $35 \mathrm{~V}$; and lockspray reference compound, leucine-enkephalin.

The acquired data were analyzed using ProteinLynx Global Server version 2.5 software with the followed settings: mode, electrospray- $\mathrm{MS}^{\mathrm{E}}$; lockmass for charge 1, 556.2771 Da; minimal fragment ion matches per peptide, 2; minimal fragment ion matches per peptide, 5 ; allowed missed cleavage, 1; fixed modifications, carbamdomethyl $\mathrm{C}$; and variable modifications, oxidation M. The databank was imported from UniProt Knowledgebase (UniProtKB, www.uniprot.org).

\section{Protein Quantification Using UPLC-Triple Quadrupole MS}

Peptide separation was performed on the same UPLC system used for peptide identification. The mobile phase B was raised from 3 to $25 \%$ in 5 min, then 25 to $30 \%$ in $2 \mathrm{~min}$, and finally 30 to $40 \%$ in $2 \mathrm{~min}$. After equilibration at $100 \% \mathrm{~B}$ for $1 \mathrm{~min}$, the system was conditioned with $3 \%$ B for 2 min before the next injection.

The triple quadrupole (TQ)-MS detection was performed on a Xevo-TQ-S equipped with an ESI source (Waters). The conditions was as follows: capillary voltage, $3.0 \mathrm{kV}$; source temperature, $120^{\circ} \mathrm{C}$; desolvation 
Table 1. Multiple reaction monitoring parameters

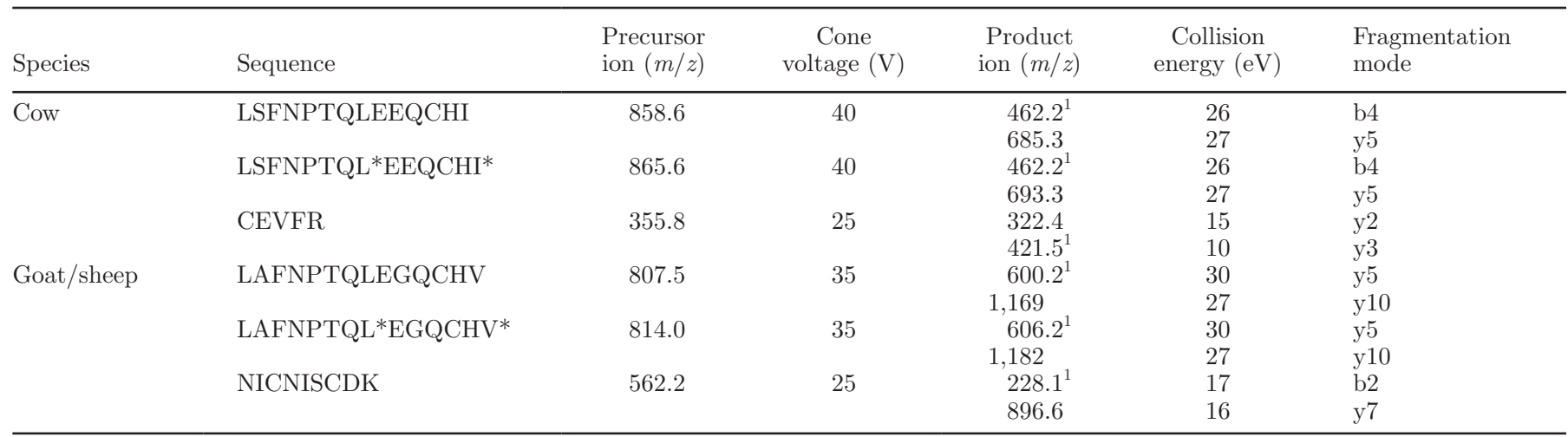

${ }^{1}$ Quantitative ion.

temperature, $500^{\circ} \mathrm{C}$; cone gas flow, $30 \mathrm{~L} / \mathrm{h}$; desolvation gas flow, $900 \mathrm{~L} / \mathrm{h}$; and argon collision gas pressure, 0.35 $\mathrm{Pa}$. The quantification was carried out using the quantitative ion peak ratio of standard and internal standard listed in Table 1. The signal ratio between quantitative and qualitative multiple reaction monitoring transition was also used to ensure the presence of peptide.

\section{Method Validation}

For the linear test, $1 \mathrm{~g}$ of $\mathrm{CM}$ powder or goat milk powder was dissolved in $100 \mathrm{~mL}$ of distilled water. The 2 solutions were mixed at ratios of $0: 10,2: 8,4: 6,6: 4$, 8:0, and 10:0. For the test of recovery and precision, 1, $5,10,50$, and $90 \% \mathrm{CM}$ was added into goat milk. The last 3 samples can also be considered as 90, 50, and $10 \%$ goat milk added into CM. The samples were prepared as described in the section Sample Preparation and Tryptic Digestion and analyzed as described in the section Protein Quantification using UPLC-TQ-MS.

\section{RESULTS AND DISCUSSION}

\section{Search for SP Candidates}

Milk proteins are classified into 2 categories: caseins and whey proteins. Both milk powder and whey protein powder are frequently used in the dairy industry. Casein was not suitable as a protein marker because of its absence in whey protein powder. Hence, the SP were based on the major whey proteins $\alpha$-LA and $\beta$-LG.

Goat milk is not used to adulterate sheep milk because of their similar economic value and vice versa. Although the separate identification of goat and sheep milk is interesting from a scientific perspective, only one peptide was selected to indicate the authenticity of GSM to reduce the difficulty and cost of the analysis for routine laboratory testing. Meanwhile, another peptide from CM protein was used to detect adulteration by CM. Although the sequences of $\alpha-\mathrm{LA}$ and $\beta-\mathrm{LG}$ from the 3 species have high identity (>90\%), 1 pair of SP candidates for $\alpha$-LA and 2 pairs for $\beta$-LG was theoretically available to identify GSM from CM (Figure 1). Because of the variation of the second $S$ to $R$ in GSM, the SP candidate of goat and sheep $\alpha$-LA could be DDQNPHSR or NICNISCDK. However, the SP candidates DDQNPHSSNICNISCDK and DDQNPHSR were not detected using UPLC-ToF under the conditions of our instrument (box 2 in Figure 1), possibly because of poor chromatographic resolution of the long peptide, efficiency of ionization, or both. The SP candidates shown in box 1 in Figure 1 were not suitable because they could be used to identify and distinguish cow, sheep, or goat milk. However, the SP for CM CEVFR together with the GSM SP NICNISCDK could be used to distinguish CM and GSM.

Two pairs of theoretical SP candidates exist in $\beta$-LG (boxes 3 and 4 in Figure 1). The SP pair in box 3 is undetectable using UPLC-ToF with the conditions of our instrument. Because Pro is directly linked after Lys in the middle of the peptide sequence, the candidate SP could not be digested by trypsin at the C-terminal of this Lys. Poor chromatographic resolution of the long peptide sequence might explain why they are undetectable. Another SP pair indicated in box 4 was detectable using UPLC-ToF with high response.

In summary, the CM SP CEVFR from $\alpha$-LA and LSFNPTQLEEQCHI from $\beta$-LG and the GSM SP NICNISCDK from $\alpha$-LA and LAFNPTQLEGQCHV from $\beta$-LG could be used as candidate SP to identify and distinguish CM and GSM. The MRM parameters for UPLC-TQ-MS are listed in Table 1, and typical chromatograms are shown in Figure 2. The peptides could be used to quantify sample adulteration based 
on milk powders and whey powder. However, only the qualitative analysis for a casein-based food, such as cheese, was possible using the above-mentioned peptides, only when $\beta$-LG remained as a residue after food processing (Camerini et al., 2016).

\section{Comparison of Digestion Process}

A sample was prepared as described in the section Sample Preparation and Tryptic Digestion. The tryptic digestion time ranged from $15 \mathrm{~min}$ to $8 \mathrm{~h}$ (Figure 3). One sample was digested for $24 \mathrm{~h}$ to ensure that the protein was completely hydrolyzed. The peak areas of the sample after $24 \mathrm{~h}$ of digestion were set as $100 \%$ to normalize the peak areas from other samples.

As previously described, the SP pairs for $\beta-\mathrm{LG}$ are at identical positions in the sequence. They might perform similarly during the tryptic digestion process. However, the SP pair for $\alpha$-LA at different positions could cause different tryptic digestion efficiency.

The results showed that $\beta$-LG was easily digested, and its SP were released completely from their proteins in $15 \mathrm{~min}$. The $2 \mathrm{SP}$ had similar physicochemical and enzymatic kinetic features because they had a similar sequence at the same position in the protein sequence. Furthermore, the $2 \mathrm{SP}$ were composed of $14 \mathrm{AA}, 11$ of which were identical. Therefore, their behaviors in liquid chromatography and TQ-MS were similar and can lead to comparable and reliable results.

Conversely, the SP for $\alpha$-LA had different characteristics in the digestion test. About 85 to $90 \%$ of CEVFR was generated after $45 \mathrm{~min}$ and its content varied within a small range. The peptide NICNISCDK was very difficult to separate from GSM $\alpha$-LA under the same digestion conditions. Even after $8 \mathrm{~h}$ of incubation, $40 \%$ of the NICNISCDK remained undetectable. Based on

$\alpha$-lactalbumin

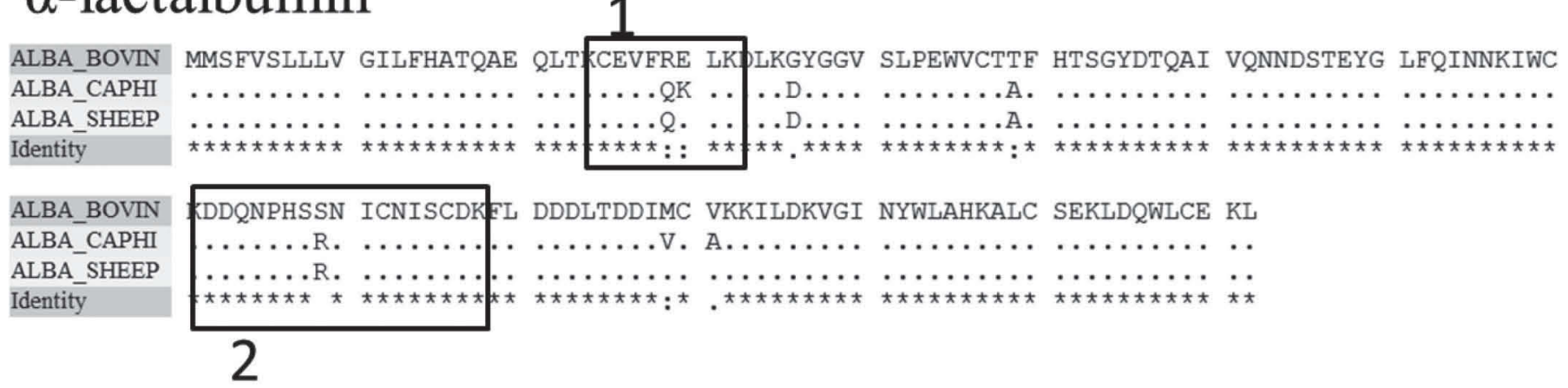

\section{$\beta$-lactoglobulin}

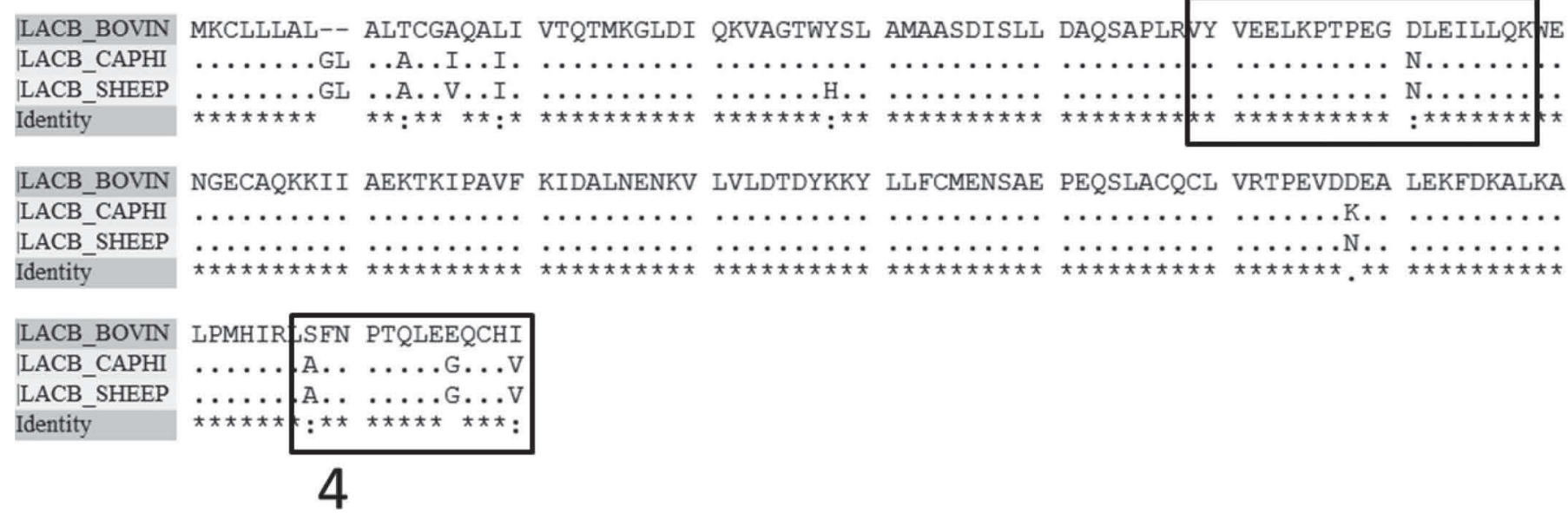

Figure 1. Alignment of $\alpha$-LA and $\beta$-LG (from top to bottom for each alignment: cow, goat, and sheep). The UniProtKB entry numbers for each protein are as follows: cow $\alpha$-LA, P00711; goat $\alpha$-LA, P00712; sheep $\alpha$-LA, P09462; cow $\beta$-LG, P02754; goat $\beta$-LG, P02756; sheep $\beta$-LG, P67976. Box 1 to 4 indicate the theoretical signature peptide candidates. 


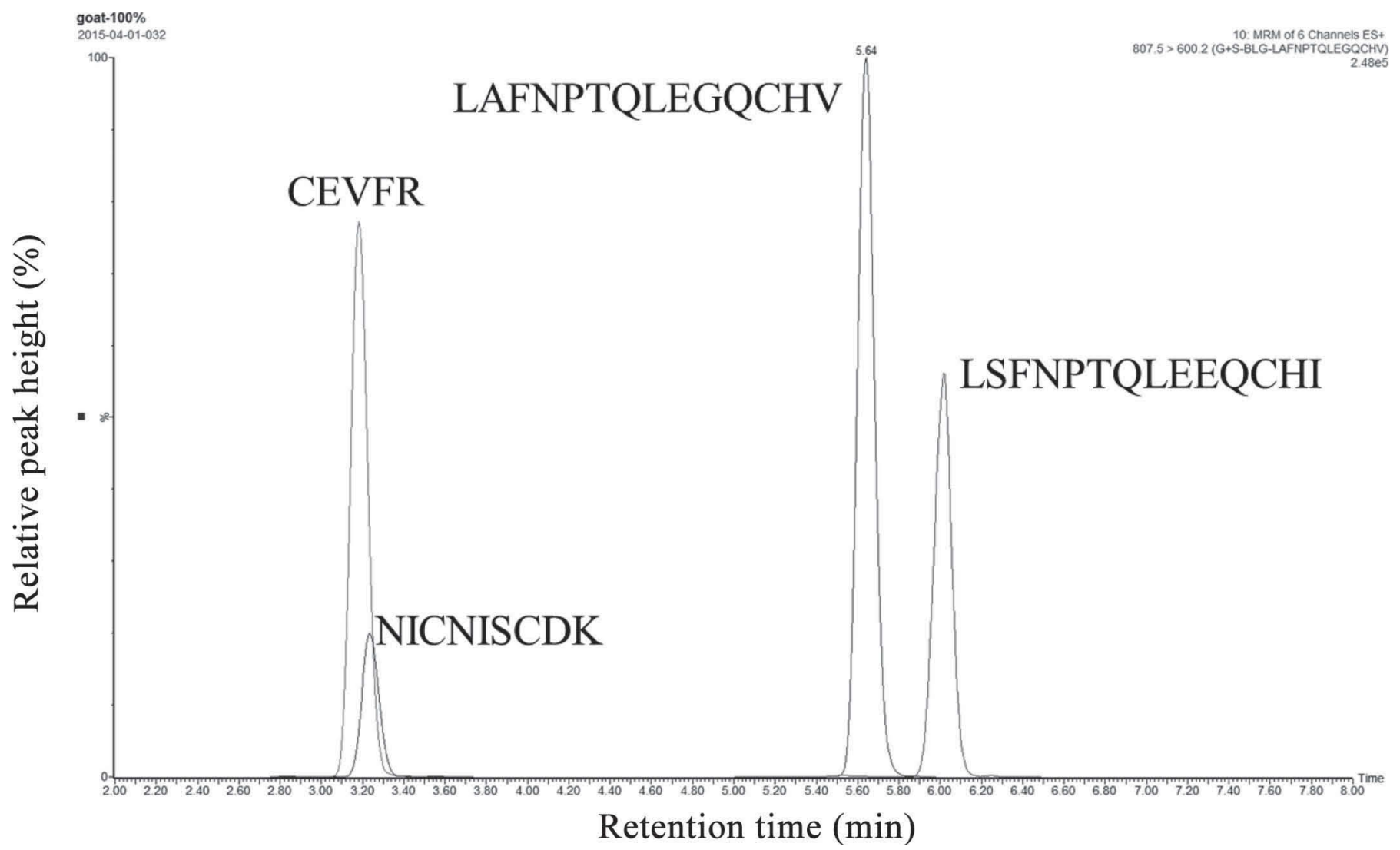

Figure 2. Chromatogram of 4 signature peptide (SP) candidates.

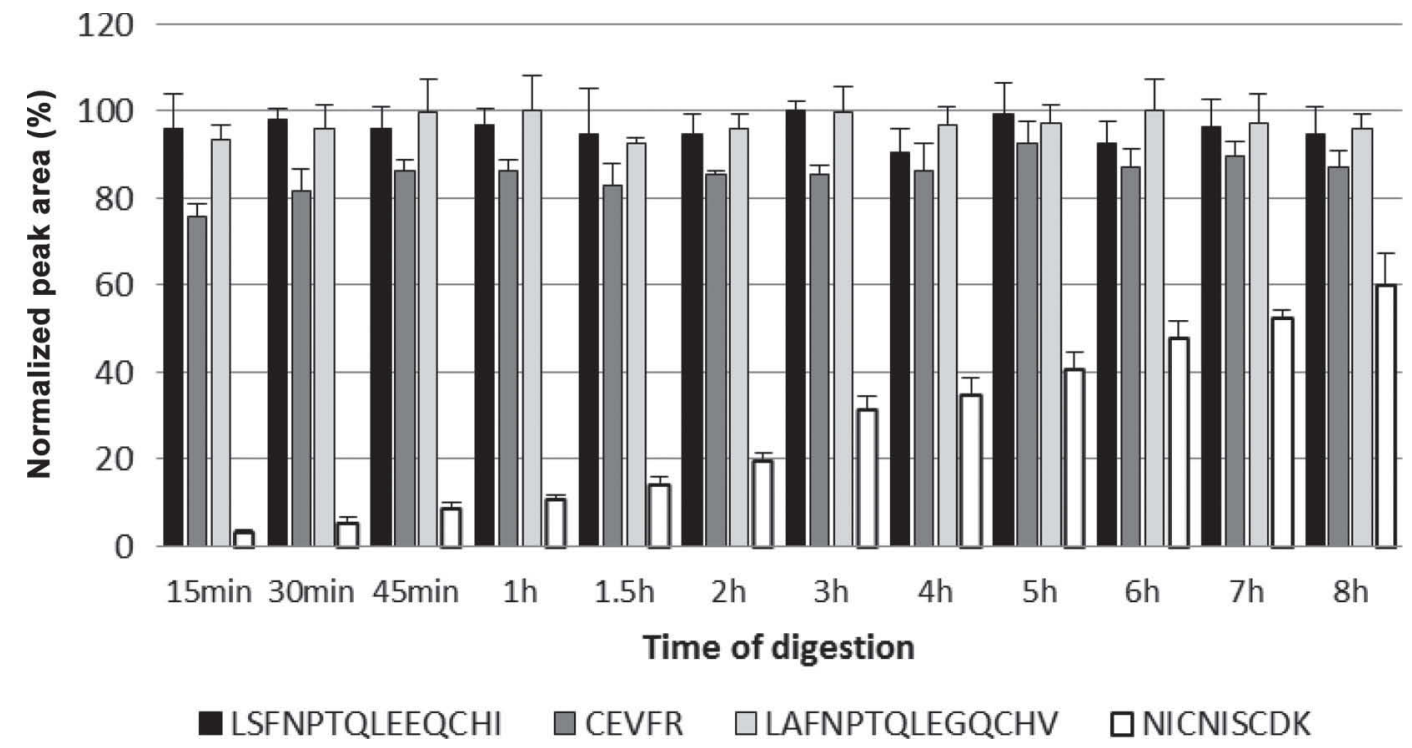

Figure 3. Relative peak areas after various tryptic digestion time. Black bars represent peptide LSFNPTQLEEQCHI from cow $\beta$-LG; dark gray bars represent peptide CEVFR from cow $\alpha$-LA; light gray bars represents peptide LAFNPTQLEGQCHV from sheep or goat $\beta$-LG; white bars represent peptide NICNISCDK from sheep or goat $\alpha$-LA. Error bars are SD of 3 replicates. 


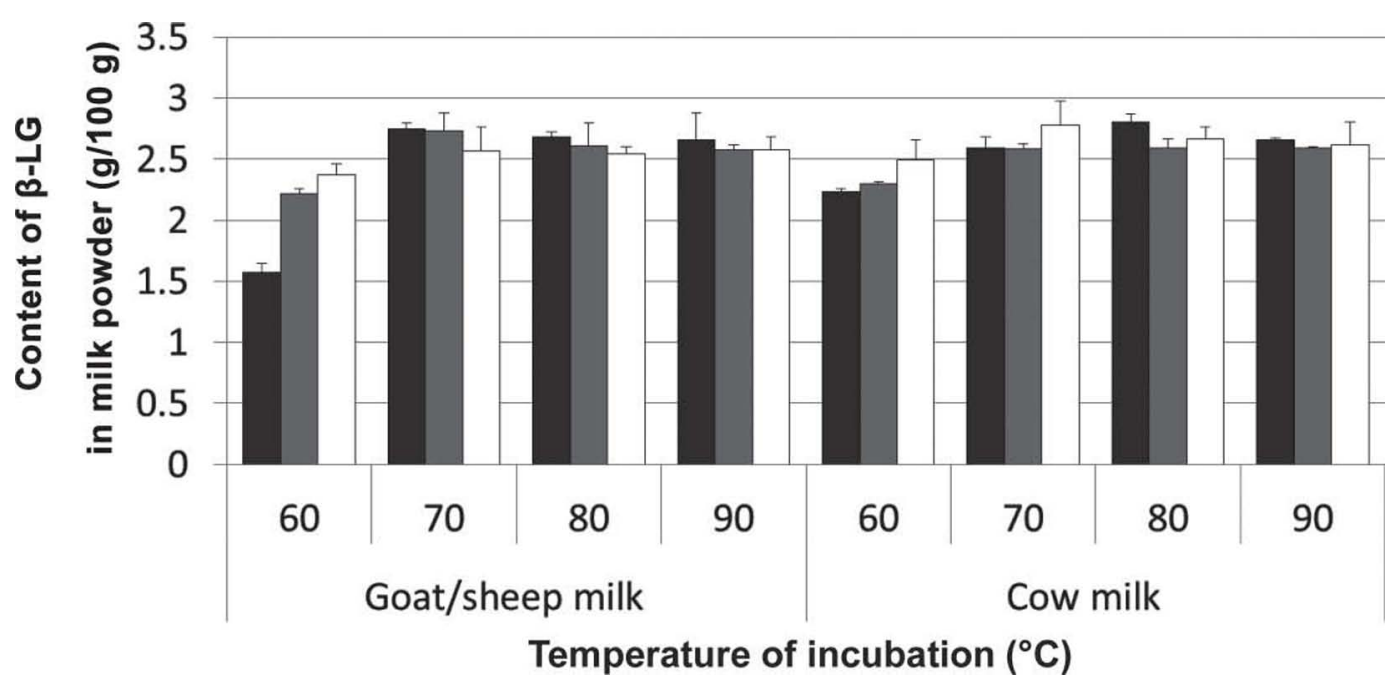

Figure 4. Optimization of temperature $\left(60,70,80\right.$, and $\left.90^{\circ} \mathrm{C}\right)$ and concentration of dithiothreitol $(\mathrm{DTT}$; black $=100 \mathrm{mmol} / \mathrm{L} ; \mathrm{gray}=250$ $\mathrm{mmol} / \mathrm{L}$; white $=500 \mathrm{mmol} / \mathrm{L})$. Error bars are SD of 3 replicates.

the preceding results, the SP pair from $\alpha$-LA was not suitable for use as a marker because of low efficiency and a possible underestimation of GSM content due to incomplete digestion.

The LSFNPTQLEEQCHI for CM and LAFNPTQLEGQCHV for GSM were finally selected as the markers. The elongated stable isotope-labeled peptides LKALPMHIRLSFNPTQL*EEQCHI* and LKALPMHIRLAFNPTQL*EGQCHV* were synthesized as IS to be spiked into samples before digestion to eliminate the matrix effect and remedy the digestion losses (Zhang et al., 2014; Chen et al., 2015). The stable isotope-labeled SP LSFNPTQL*EEQCHI* and LAFNPTQL*EGQCHV* were released from the IS after incubation with trypsin.

\section{Optimization of Sample Preparation}

In addition to their primary structure, proteins have more complicated 3-dimensional structures. Some cleavage sites inside proteins might cause incomplete digestion. To reduce the difficulty of digestion, DTT was used to break the disulfide bonds of proteins (Zhang et al., 2014; Chen et al., 2015). However, only 1.57 $\mathrm{g} / 100 \mathrm{~g}$ of $\beta-\mathrm{LG}$ was detected in a GSM sample after treatment with $100 \mathrm{mmol} / \mathrm{L} \mathrm{DTT}$ at $60^{\circ} \mathrm{C}$ for $30 \mathrm{~min}$, which is significantly less than the theoretical value of 2 to $3 \mathrm{~g} / 100 \mathrm{~g}$. The content could not be increased by increasing the concentration of trypsin or extending the duration of digestion. To improve the digestion efficiency, an orthogonal test was designed. Dithiothreitol was prepared with water at 100,250 , and 500 $\mathrm{mmol} / \mathrm{L}$. The incubation temperature was set at 60 , 70,80 , and $90^{\circ} \mathrm{C}$. Indoleacetic acid was prepared at the same concentrations and added with 3-fold more DTT in samples. Other parameters remained unchanged.

As shown in Figure 4, the content of $\beta-\mathrm{LG}$ was significantly increased with a higher concentration of DTT at the incubation temperature of $60^{\circ} \mathrm{C}(P<0.05)$. The content of $\beta$-LG remained increased even if the temperature was above $70^{\circ} \mathrm{C}$ when using $100 \mathrm{mmol} / \mathrm{L}$ DTT. At this temperature, the concentration of DTT improved the tryptic digestion. The high temperature might break noncovalent bonds, including hydrogen bonds, which could cause proteins to refold. After the noncovalent bonds were broken, we deduced that the cleavage sites were exposed for digestion. In addition, the disulfide bonds hidden inside the 3-dimensional structure were also exposed to DTT, which we deduced could possibly cause more intensive refolding of proteins.

\section{Method Validation}

Method validation was carried out using a cow and goat milk powder. The validation results with cow and sheep milk were similar (data not shown).

Selectivity. An in silico test performed using the basic local alignment search tool (BLAST, www.uniprot. org/blast/) function in UniProtKB did not show any cross activity. Considering the incomplete protein data in the current proteomics database, CM, goat milk, and sheep milk were individually prepared and analyzed. The results shown in Figure 5 do not reveal any cross activity.

Linearity. The linear equations for $\mathrm{CM}$ and goat milk was $y=1.45629 x+6.67293$ and $y=1.1694 x+$ 0.0130456 , respectively. To detect a small concentration 


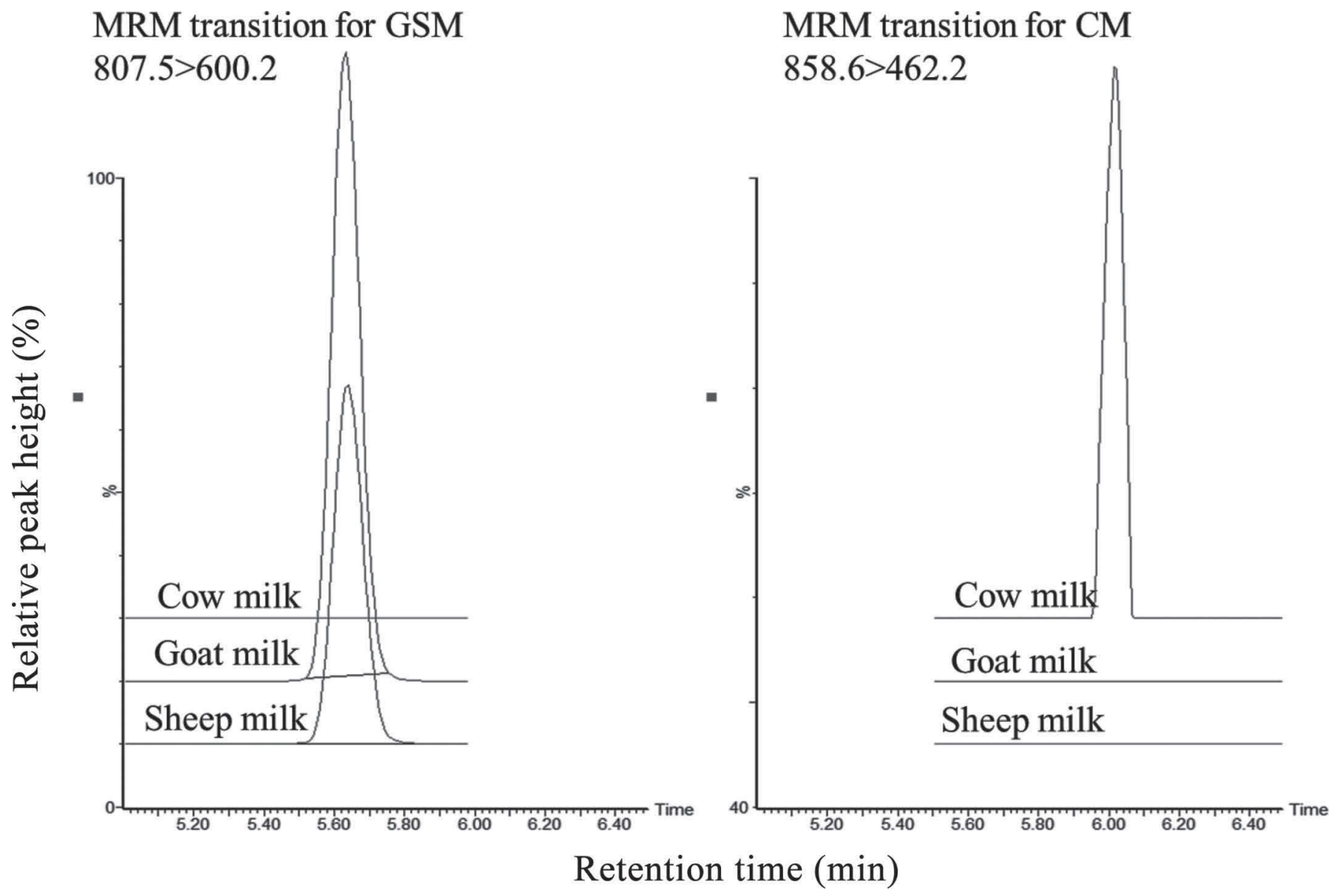

Figure 5. Specific selectivity test of pure cow, goat, and sheep milks in 2 multiple reaction monitoring $(\mathrm{MRM})$ channels. CM $=$ cow milk; GSM $=$ goat and sheep milk.

of CM, 2, 4, 6, 8, and $10 \% \mathrm{CM}$ solution was added to goat milk. The linear equation was $y=1.11854 x+$ 5.76003. Good linearity and coefficients $\left(\mathrm{R}^{2}>0.99\right)$ were obtained from the 3 calibration curves.

Recovery, Precision, and Limit of Quantification. For the recovery test, every sample was analyzed

Table 2. Recoveries and relative standard deviations (RSD) of cow and goat milk content in a spiked sample of goat and cow milk mixture at the designed percentages $(n=24)$

\begin{tabular}{llcc}
\hline Milk & $\begin{array}{l}\text { Designed } \\
\text { percentage }\end{array}$ & $\begin{array}{c}\text { Recovery } \\
(\%)\end{array}$ & $\begin{array}{c}\text { RSD } \\
(\%)\end{array}$ \\
\hline Cow milk & 1 & 104.4 & 4.5 \\
& 5 & 101.1 & 5.3 \\
& 10 & 102.2 & 6.5 \\
& 50 & 96.9 & 4.3 \\
Goat milk & 90 & 101.1 & 5.1 \\
& 10 & 101.0 & 5.7 \\
& 50 & 96.2 & 6.0 \\
& 90 & 100.2 & 4.6 \\
\hline
\end{tabular}

using 6 replicates per day, continuously for $4 \mathrm{~d}$. The recoveries ranged from 96.2 to $104.4 \%$. The interday precision, expressed as relative standard deviation, was 4.3 to $6.5 \%$ (Table 2). The limit of quantification of this established method was determined as $1 \%$ of $\mathrm{CM}$ in a sample, which showed a good accuracy and repeatability.

The validation with $\mathrm{CM}<1 \%$ or goat milk $<10 \%$ was not carried out because these levels of adulteration would not occur for economic reasons.

Profession Test. A profession test, in which we obtained samples with unknown content of $\mathrm{CM}$ and GSM and analyzed them to let an independent institute check the accuracy of the present method, was performed with the support of National Center for Quality Supervision and Inspection of Dairy Products in China. Four blind samples were produced by mixing $\mathrm{CM}$ and goat milk at different ratios and lyophilizing them. The results acquired by the current method showed high accuracy for CM content (Table 3). However, the amount 
Table 3. Comparison of designed percentage of goat and cow milk in blind samples and analytical results using the present method $(\mathrm{n}=3)$

\begin{tabular}{lccccc}
\hline & \multicolumn{2}{c}{ Designed percentage } & & \multicolumn{2}{c}{ Analyzed percentage (mean \pm SD) } \\
\cline { 2 - 3 } \cline { 5 - 6 } Sample & Goat milk & Cow milk & & Goat milk & Cow milk \\
\hline 1 & 50 & 50 & & $62.1 \pm 0.1$ & $53.9 \pm 2.0$ \\
2 & 75 & 25 & & $87.9 \pm 3.9$ & $24.3 \pm 0.3$ \\
3 & 90 & 10 & & $95.0 \pm 4.2$ & $8.0 \pm 0.7$ \\
4 & 99 & 1 & & $102.2 \pm 1.7$ & $0.80 \pm 0.02$ \\
\hline
\end{tabular}

of detected goat milk was little more than the designed content. The deviation might have been caused by the different goat milk used to prepare the blind samples and standard curve.

\section{Comparison Between the Current Method and Commercial Kits}

Two semiqualitative ELISA kits (against cow IgG and casein) and a test strip kit (against IgG) were obtained from R-Biopharm (Beijing, China). Five milk powder samples (samples 1-5) were purchased from the local market, and 3 samples were mixed with fresh $\mathrm{CM}$ and goat milk in our laboratory (samples 6-8). A sheep whey powder (sample 9) was obtained from the Beingmate Baby \& Child Food Co., Ltd.. The ELISA and strip kits using IgG as a marker provided accurate results for fresh milk but false-positive results for the milk powder sample (Table 4), perhaps because the denatured IgG (after spray drying) was not correctly recognized by the antibody. Underestimated results were obtained with the ELISA kits against casein compared with the other tests, even for fresh milk samples. Although the ELISA kits against casein were designed as semiquantitative kits, the quantitative range was very small and the extinctions for positive samples were very close to negative samples. It was difficult to confirm the quantitative result when the standard deviation was also considered.

The results for the fresh milk samples by the current UPLC-TQ-MS method matched expectations. The sum of CM and GSM content of milk powder samples was only 80 to $90 \%$ of their total weight, probably because of the natural variation of $\beta-L G$ in samples and standard.

The sheep whey sample was analyzed using the milk powder as the standard. The whey contents were calculated by the theoretical whey protein percentage (Fox and McSweeney, 1998). The results of ELISA were underestimated, and the strip test was negative. One of the ELISA kits was against casein, however, which was not present in whey powder. The underestimated results from ELISA kit and strip test were also due to protein denaturation.

\section{Analysis Result of Commercial Samples}

We purchased 8 goat or sheep milk powders from the local market and obtained 5 goat milk powders and 5 goat or sheep whey powders as raw materials from

Table 4. Comparison of results using ultra-performance liquid chromatography triple quadrupole MS (UPLCTQ-MS), ELISA, and Strip

\begin{tabular}{lcccccc}
\hline & \multicolumn{2}{c}{ UPLC-TQ-MS $(\mathrm{g} / 100 \mathrm{~g})^{1}$} & & \multicolumn{2}{c}{ ELISA against $(\%)$} & \\
\cline { 2 - 3 } Sample & CM & GSM & & Cow IgG & Cow casein & $\begin{array}{r}\text { Test strip against } \\
\text { cow IgG }^{2}\end{array}$ \\
\hline 1 & 3.8 & 86.1 & & $<0.1$ & $>1$ & - \\
2 & 0 & 87.3 & & $<0.1$ & $<0.5$ & - \\
3 & 4.5 & 77.8 & & $<0.1$ & $<0.5$ & - \\
4 & 9.1 & 83.7 & & $<0.1$ & $>1$ & - \\
5 & 16.7 & 68.1 & & $<0.1$ & $>1$ & + \\
6 & 1.1 & 97.6 & & $1-10$ & $<0.5$ & + \\
7 & 4.8 & 95.8 & & $1-10$ & $0.5-1$ & + \\
8 & 10.8 & 88.2 & & $1-10$ & $0.5-1$ & - \\
9 & 0 & 84.6 & & $<0.1$ & $<0.5$ & - \\
\hline
\end{tabular}

${ }^{1} \mathrm{CM}=$ cow milk; GSM $=$ goat and sheep milk.

${ }^{2}$ Negative (-) or positive (+). ELISA kit against cow IgG (Art. No.: R4652) and casein (Art. No.: R4612) and test strips against cow IgG (Art. No.: BL613-25) were obtained from R-Biopharm China (Beijing, China). Samples 1-5 were purchased from a local market, samples 6-8 were mixed by fresh CM and goat milk; sample 9 was sheep whey powder. 
Table 5. Analysis results of commercial samples using the present method; samples were purchased from local market and obtained as raw material ${ }^{1}$

\begin{tabular}{lcc}
\hline Sample no. and type & $\begin{array}{c}\text { CM } \\
(\%)\end{array}$ & $\begin{array}{c}\text { GSM } \\
(\%)\end{array}$ \\
\hline Milk powder purchased from local market & 3.8 & 92.6 \\
1 & 0 & 93.9 \\
2 & 3.8 & 86.1 \\
3 & 0.0 & 87.3 \\
4 & 4.5 & 77.8 \\
5 & 95.8 & 0.0 \\
6 & 9.1 & 83.7 \\
7 & 16.7 & 68.1 \\
8 & & \\
Milk powder as raw material & 0 & 102.8 \\
9 & 0 & 83.6 \\
10 & 0 & 89.4 \\
11 & 0 & 96.5 \\
12 & 8.8 & 73.1 \\
13 & & \\
Whey powder & 1.4 & 109.6 \\
14 & 0 & 105.6 \\
16 & 0 & 102.0 \\
\hline
\end{tabular}

${ }^{1} \mathrm{CM}=$ cow milk; GSM $=$ goat and sheep milk.

the production department of Beingmate Baby \& Child Food Co. Ltd. None of the samples declared the presence of CM. The analysis results were normalized with the total protein content determinate by the Kjeldahl method. The results are shown in Table 5. Generally, the sums of CM and GSM were not $100 \%$, possibly because of the natural variation of $\beta$-LG content between the milk powder used as standard and samples. The milk content was calculated from $\beta$-LG with a factor. The factor can be changed if a different milk powder is used as the standard and sample. Even if they are produced from the same raw milk, whole milk powder and skim milk powder can differ by up to $>20 \%$, because the fat content in whole milk powder is between 24 and $26 \%$.

Of the samples purchased from the local market, only sample 4 did not contain any CM. In contrast, sample 6 containing only CM powder was clearly adulterated. Other samples containing 3.8 to $16.7 \% \mathrm{CM}$ powder could not be categorized as being adulterated because cross-contamination may have occurred during production. The milk powder and whey powder used as raw materials had less adulteration than the samples from the local market.

\section{CONCLUSIONS}

The present work introduced a method to identify and quantify CM and GSM using UPLC-TQ-MS. After comparison of proteins and peptides, signature peptides from $\beta$-LG were selected as markers. The sample prepa- ration method was optimized to make tryptic digestion easier and more complete. The results of single laboratory validation and profession test showed high accuracy, selectivity, linearity, and precision for the present method. The method using only 2 peptides as markers is cost effective and easy to adopt for routine laboratory analysis. It is worth noting that the commercial kits only indicated the presence of CM in a sample; they could not prove whether GSM was present. The current UPLC-TQ-MS method could simultaneously provide 2 results for both types of milk, which was more reliable and traceable.

\section{ACKNOWLEDGMENTS}

We thank B. J. Liao and L. L. He from R-Biopharm (Beijing, China) for providing the ELISA kits and technical support during this study.

\section{REFERENCES}

Abdel-Rahman, S., and M. Ahmed. 2007. Rapid and sensitive identification of buffalo's, cattle's and sheep's milk using species-specific PCR and PCR-RFLP techniques. Food Contr. 18:1246-1249.

Bernardi, N., G. Benetti, N. M. Haouet, M. Sergi, L. Grotta, S. Marchetti, F. Castellani, and G. Martino. 2015. A rapid high-performance liquid chromatography-tandem mass spectrometry assay for unambiguous detection of different milk species employed in cheese manufacturing. J. Dairy Sci. 98:8405-8413.

Camerini, S., E. Montepeloso, M. Casella, M. Crescenzi, R. M. Marianella, and F. Fuselli. 2016. Mass spectrometry detection of fraudulent use of cow whey in water buffalo, sheep, or goat Italian ricotta cheese. Food Chem. 197:1240-1248.

Cartoni, G., F. Coccioli, R. Jasionowska, and M. Masci. 1999. Determination of cows' milk in goats' milk and cheese by capillary electrophoresis of the whey protein fractions. J. Chromatogr. A 846:135-141.

Chen, Q., J. Zhang, X. Ke, S. Lai, B. Tao, J. Yang, W. Mo, and Y. Ren. 2015. Quantification of bovine $\beta$-casein allergen in baked foodstuffs based on ultra-performance liquid chromatography with tandem mass spectrometry. Food Addit. Contam. Part A Chem. Anal. Control Expo. Risk Assess. 32:25-34.

Costa, N., F. Ravasco, R. Miranda, M. Duthoit, and L. Roseiro. 2008. Evaluation of a commercial ELISA method for the quantitative detection of goat and cow milk in ewe milk and cheese. Small Rumin. Res. 79:73-79.

Cottenet, G., C. Blancpain, and P.-A. Golay. 2011. Simultaneous detection of cow and buffalo species in milk from China, India, and Pakistan using multiplex real-time PCR. J. Dairy Sci. 94:37873793.

Czerwenka, C., L. Müller, and W. Lindner. 2010. Detection of the adulteration of water buffalo milk and mozzarella with cow's milk by liquid chromatography-mass spectrometry analysis of $\beta$-lactoglobulin variants. Food Chem. 122:901-908.

Di Girolamo, F., A. Masotti, G. Salvatori, M. Scapaticci, M. Muraca, and L. Putignani. 2014. A sensitive and effective proteomic approach to identify she-donkey's and goat's milk adulterations by MALDI-TOF MS fingerprinting. Int. J. Mol. Sci. 15:13697-13719.

Ferreira, I. M., and H. Caçote. 2003. Detection and quantification of bovine, ovine and caprine milk percentages in protected denomination of origin cheeses by reversed-phase high-performance liquid chromatography of beta-lactoglobulins. J. Chromatogr. A 1015:111-118. 
Fox, P. F., and P. L. McSweeney. 1998. Dairy Chemistry and Biochemistry. Springer Science \& Business Media, Cham, Switzerland.

López-Calleja, I., I. G. Alonso, V. Fajardo, M. Rodríguez, P. Hernández, T. García, and R. Martín. 2005. PCR detection of cows' milk in water buffalo milk and mozzarella cheese. Int. Dairy J. 15:11221129.

López-Calleja, I., I. González, V. Fajardo, I. Martín, P. Hernández, T. García, and R. Martín. 2007a. Real-time TaqMan PCR for quantitative detection of cows' milk in ewes' milk mixtures. Int. Dairy J. 17:729-736.

López-Calleja, I. M., I. González, V. Fajardo, P. E. Hernández, T García, and R. Martín. 2007b. Application of an indirect ELISA and a PCR technique for detection of cows' milk in sheep's and goats' milk cheeses. Int. Dairy J. 17:87-93.

Mayer, H., D. Heidler, and C. Rockenbauer. 1997. Determination of the percentages of cows', ewes' and goats' milk in cheese by isoelec- tric focusing and cation-exchange HPLC of $\gamma$-and para- $\kappa$-caseins. Int. Dairy J. 7:619-628

Park, Y. 1994. Hypo-allergenic and therapeutic significance of goat milk. Small Rumin. Res. 14:151-159.

Raynal-Ljutovac, K., A. Pirisi, R. De Cremoux, and C. Gonzalo. 2007. Somatic cells of goat and sheep milk: analytical, sanitary, productive and technological aspects. Small Rumin. Res. 68:126-144.

Song, H., H. Xue, and Y. Han. 2011. Detection of cow's milk in Shaanxi goat's milk with an ELISA assay. Food Contr. 22:883-887.

Zhang, J., S. Lai, Z. Cai, Q. Chen, B. Huang, and Y. Ren. 2014. Determination of bovine lactoferrin in dairy products by ultra-high performance liquid chromatography-tandem mass spectrometry based on tryptic signature peptides employing an isotope-labeled winged peptide as internal standard. Anal. Chim. Acta 829:33-39. 